\title{
Investigate the Relationship between Parenting Styles with Development of Moral Judgment in Children 4 - 6 Years in Kindergartens of the City of Babol
}

\author{
Zubaideh Babajanzadeh \\ Master of Psychology, University Ayatollah Amoly \\ Dr. Arsalan Khan Mohammadi Otaghsara \\ Assistant Professor University Ayatollah Amoly
}

Doi:10.5901/mjss.2016.v7n2s2p92

\begin{abstract}
In the present study, the relationship of parenting styles on children's moral judgment development 4-6 years of the city of babol was in kindergarten. The study population consisted of 1320 person of preschool in kindergarten of babol during the year 2014-2015, among them 100 numbers was selected with multistage random cluster sampling method, The tool of measurement consisted of the parenting style questionnaire Bamrind and Mut questionnaire. In this study, was used descriptive statistics, correlation and multiple regressions. The results showed there was a significance relationship between authoritative and authoritarian style and children's moral development, but there was not a significant relationship between parenting style landscape and moral development.
\end{abstract}

Keywords: Parenting styles, the development of moral judgment.

\section{Introduction}

Any sane person accepts the reciprocal relationship between parents and children and there is a bilateral process. The interaction of parental behavior on children's mood, which is an important element in the growth that is known the two strains. Under this principle, the relationship between parent - child interactive, and that parental behavior affects children and children affected (Kazvdyn, 2005). Psychologists have always been interested to study the effects ways of parenting on the growth capabilities of the social children, one of the most important issues in this area is called parenting (Darling and Steinberg, 1993). Parenting is a complex activity, including methods and specific behaviors that separate or interact with each other to affect child development. In fact, the basis of parents parenting styles represent attempts to control the children's social (Bamrind, 1993). Changes normal involved in the interaction between parents and children in relations between parents and children. Recognition normal changes were considered in parent-child interaction of the key elements is the dynamic approach (Collins and Madsen, 2003).

\section{Research Literature}

Family is the first base that creates the bond between the child and her child in the environment. The child learns about the world's first opinion and grows the mentally and physically, learns the ways of speaking. And finally learns the basic norms of behavior, attitudes, ethics and social behavior are shaped. In other words, socialize. (Zahra kar, 2008). Each family in the upbringing of their children will use a particular style. Set of attitudes, actions and non-verbal and verbal statements from the parents of the nature of parent-child interactions in specific situations is known as parenting style (sliker et al., 2005). Many parents change educational methods in accordance with children's capacities and behaviors. For example, a longitudinal study of a group of mothers reported that their children between the ages of 7 to 8 years in compared with the age of 15 to 16 years of theire ducational methods are more stable. They said that in midadolescence increased their surveillance on children; since at this age children spend more hours outdoors (McNally, Essen leaves and Harris, 1991).

Parenting styles have significant effects on children's behavioral anomalies. The quality of parental behavior on academic performance, peer relations and adjustment in adolescenceis marked (Mac Cui, 1984; quoted Azkazvdyn, 
2006)). Various methods have been proposed for parenting, (Baumrind 1971) proposed three styles parenting are:

A) authoritative parenting b) Permissive mode c) authoritarian style

Mac Cui and Martin (1983) negligent manner also added to three Baumrind's method.

Parenting style has two basic components:

A) response (intimacy and reassurance) as much as parents trying to develop assertiveness and independence in children, support and reassurance to children and their needs refers (Baumrind, 1991).

B) requests from parents (behavioral control) to try to attract parents and children in the family through the family unification applications according to the abilities of children, their monitoring and regulation refers (Baumrind, 1991). Hoffman (1970) reviewed research related to parenting and to obtain results about the effects of parenting styles on children's moral development.

The results showed that: (1) lack of love for children and emphasized the power of a positive effect on their children's moral maturity. 2. The inductive method on all three aspects of emotional moral, ethical, moral and ethical behavior has a positive impact (Hoffman, quoted Shaffer, 1996).

In human societies, different cultures ethics are of the most important factors that have always been of interest to sociologists and psychologists. So they ware constantly discovering and recognition development fields and creating the largest source psychological and human. The moral rules type of social rules. Encouraging people to do good deeds and righteousness guarantee and identify good and bad actions. In addition, children should learn moral and social rules that may be in different positions; there were many differences between them. Human are born with a moral sense. This feeling appears in the family, they models from teachers and is fed through community. In fact, family, school and community training moral rules based on the principles of justice and taking into account the situation of the rights of others,(Masen and.et al, 1993; Quoted fromKhakpour and et al, 2012)

\section{Parenting Style}

Parenting styles can be seen as a set of behaviors that gives described parents -child interactions over the range of extensively opportunities (Alizadeh Vandrys, 2002), In other words Baumrind (1991),Which Interact with outstanding longitudinal studies of parents with their children's and parenting style including a variety of different behaviors.

(Baumrind, 1991, as quoted by Darling, 1999). He knows that parenting is a complex activity, including Methods and special treatment and separate or interact with each other to affect the child's development. In fact, the basis for parenting styles and socialization represents the efforts of parents to control their children.

Despot: Authoritarian parents often take to humiliation their children and punishment applied, not any explanation. (Laybl and Thompson, 2002).

Parents who use authoritarian style also are expected, but to follow it so value that children do not like to follow. "The same work that I do" attitude of the parents. As a result, they expect their children obedience of adults commands, unquestioning.pay less to talk with them. If the child does not obey, despot parental uses pressure and punish.

Authoritarian parents do not see the need that present reason for commands.

In their view unquestioning obedience is a Excellence (Seyed Mohammadi, 2004).

Authoritative style: authoritarian and permissive parenting styles are placed on either side of one. In front of a strong light is placed somewhere between the two parents who were working style to better suit your child show and the parental controls are medium to which children are allowed the increasingly autonomous (Ritman et al., 2002; quoted Doiyri et al., 2006).

Authoritative parenting style is the most appropriate method. Authoritative parents to maturity are reasonable requests and perform demands by determining limits and insisting that children must be subordinate.

At the same time, they show sincerity and affection, patiently listen to children's views and encourage participation in the decision-making family. Authoritative parenting, rational and democratic manner in which the rights of parents and children are respected.Parents insist on will of free and discipline. They encourage relationship verbal and exchanges and when uses his authority as a parent and forbidden child of something, or have expectations of him and brought up reason (Azadi, 2003).

Permissive Style: Parents who use this style, merciful and receptive, but are not expected and refuse from any control action. Permissive parents to let their children to decide for themselves at any age that children are. (Seiyed Mohamadi,2004). Parents have a permissive parenting style, there are two models: permissive parents over and permissive parents indifferent. Parents are permissive and over they are friendly and supportive and usually are sensitive to work and emotion's childrens. However, a low level of control exercised and have demands a relatively minor of children. Verbal and nonverbal relations are warm and with love, care for their children. Less clearly their views in 
situations that children should be limited. Indifferent parents, on this model of education, parents do not involvement emotional with their children and some kind of emotional breakdown in the relationship with their children. Parents are dissimilar to create and maintain criteria, standards, expectations and responsibilities (Sharifi, Fajiri, 2007). Permissive parenting style in childhood causes children with lack of self-esteem, low self-esteem and self-control defect in learning ethical issues and social constraints (Azadi, 2003).

\section{Moral Development}

Moral word comes from the Latin word mos that means action on customs and way of doing things. So as to adapt to the ways of human beings and of right and wrong and good behavior. People generally believed that the word means good behavior, and correct and true. According to Piaget, moral development that resulted from the growth of social experience, the sense of respect for the law and social justice (Lotfabadi, 2006). From the perspective of Kohlberg (1980), the aim of teaching them morals and ethics to act to bring the child's ability to judge, to him be given the opportunity to control their behavior to take advantage of good judgment.

\section{The Development of Moral Judgment Kohlberg}

Level 1. Pre-conventional morality - Stage 1. Obedience and punishment orientation: Children believe that people in power have developed a fixed set of rules which he must obey without question it. When the child is asked to give a more detailed explanation, usually considers the consequences of that action (Kohlberg, 1958). Kohlberg naming stage 1 thinking Pre-conventional, because children do not speak as members of society. But they treat morality as something external to themselves (Colby, Kohlberg, and Hoffman, 1987).

Step 2. Individualism and Exchange: At this stage, children will find that there was not only a true vision that is developed by the authorities there and different people have different views. Since everything is relative, so everyone is free to pursue his own personal interests (Kohlberg, 1963).

Level 2. Conventional morality - stage 3 Good interpersonal ethics contractual. At this stage, children are usually aged 11 and more, morality is no longer a simple process not considered. They believe that people should live and behave according to the expectations of family and society and they have "good" behavior. Good behavior means having good motives and interpersonal feelings such as love, sympathy, trust and respect to others (Kohlberg, 1958).

Step 4. Maintaining social order: in step 4. On the contrary, the respondents have been considering their wider community as a whole. Now the emphasis is on obeying the rules, respect for the people with authority and duty to maintain social order (Colby et al., 1987).

Level 3: Ultra-Conventional morality - Step 5. The social contract and individual rights: In stage 5, people ask themselves what factors building a good society? They are thinking in theoretical about society and are separated from their social conditions and the rights and values that a society should have been considered. Then existing communities by taking these criteria into consideration and in view of achieving Ultra-society (Colby et al., 1987).

Step 6. Universal principles: Kohlberg believes that there was should be the upper level- level 6 that principles determine our way through them to justice. Kohlberg would say that we can look at the situation through the window eyes each other, to achieve justice. About Heinz this means that all the parties involved, including Heinz and pharmacist and husband Heinz, take each other's role.

People are for objective judgment, can "mask of ignorance" in their face (Rawls, 1971) and they think that they do not know what the outcome will assume the role. If a pharmacist herself as wife left Heinz, was no doubt that the life of a human being is far more important than wealth. He never wanted to be the wife of Heinz. Thus, all were in agreement that have saved the patient's life, the solution is fair. It should be noted that such a solution requires not only neutral, but also requires the adoption of the principle that all people are respected as equal. If Heinz's wife to other considered less or inferior, just solution will be not realized. Kohlberg until 1975 some of his subjects in step 6 graded but later withdrew it. One reason for this action was that he and other researchers found very few subjects that at this stage argue somehow matched. Kohlberg also concluded that the interview did not reveal differences between steps 5 and 6 . Theoretically Step 6 has been more explicit and broader concept of universal principles that include of justice and human rights, but the interview does not assess such a wide understanding. Therefore, Stage 6 was removed from the guidelines and naming the 'theoretical' and the entire after contract answers scoring at Step 5 (Crane, 2012). In step 6, commitment to justice, disobedience citizen Legtimize stronger and broader. Martin Luther King believed that rules are valid until fair and the 
commitment to justice, the requirement to bring the rules to avoid abnormal. He also stressed the need for laws and democratic processes (Kohlberg, 1981).

\section{Background Research}

A study by Khakpur and Mehrafarid was done as moral judgment in (2012) five- and six-year-old preschoolers in Qarvch city, 108 students randomly were analyzed using four-parable. The results showed that preschools children in items lie, material damage, and theft more attention to the intention (Intrinsic motivation), and the justice items were believed to be unfair. Amount attention to intention increase with increasing age. According to the result of work reduced with increasing age. Older children (six years) to all items pay more attention to their intention in moral judgment. In all three items, girls had more interest in the outcome and effect compared with boys, but boys had the intention to pay more attention than girls. In the meta-analysis of moral transformation studies was done over the years 1986 -2009 by Shabani (2009), fortyfive quantitative research were selected in the field of moral development with the concepts of moral development, moral judgment and moral behavior. The results of the meta-analysis showed that the effect of moral development by 3721 with $\% 95$ confidence intervals were significant degree of freedom and the moral judgment with 531 degrees of freedom and a confidence interval of $\% 95$ is significant.

Amount of influence moral behavior with degrees of freedom 347 and 18 with $\% 95$ confidence intervals were not significant. A study by Seyed Mosavi et al (2008) with title investigation the relationship between parenting styles and externalizing symptoms in children 7 to 9 years of age, 273 persons subjects were selected from elementary schools. The results showed that permissive parenting style with externalizing symptoms was significant positive relationship. But authoritative style with externalizing symptoms showed a significant negative correlation. There was no significant relationship between authoritarian parenting style and externalizing symptoms. To determine the relationship between mother's parenting practices (authoritative, authoritarian, permissiveness) and child perception of practices and locus of control and self-concept of children in Tehran by Pourabdoli et al (2008) was performed. The population of this study consisted of male students in grade three, as well as their mothers with at least fifth and higher education. Results showed that mother's parenting practices and locus of control and self-awareness, there is no significant relationship. The relationship between mother parenting students practices (authoritative, authoritarian, permissiveness) and locus of control and self-awareness, a significant relationship was observed. The results showed that children's perception of parenting style as a contributing factor external a better explanation locus of control and self-concept of for the formation of the child can have in the mother's attitude to these practices. Boromand Nasab (1994) in a study with title "The Relationship between parenting attitudes and practices with third grade students in the city of Dezful locus of control" sample 120 students were analyzed. The results showed that parents who expect their children to have more internal and reward your children's activities, in terms of responsiveness (warmth, acceptance and commitment) and participants (control and monitoring) at a high level and to the way their children behave reasonably authority, children become internal controls, But if parents behavioral prohibitive, restrictive and dismissive criticism hostility apply to children and be responsive to their children and applicants at a low level and style authoritarianism and permissiveness with their children treat their child has a place to be outside. In a study by Akrami (1992) to compare the moral judgment of children and juvenile offenders with normal children took to the conclusion that there was a significant difference between moral judgment and moral sense in terms of children's normal growth levels more developed has been with Kohlberg stages. Maryn and colleagues (2014), in his longitudinal study of temperament, parenting and moral development in the behavioral characteristics of the role of parenting behavior, especially in certain areas in determining the moral development of children's time. The results showed that the moral behavior of children 5.5 years the behavior of parents in particular can inhibit or predict the moral dimensions of a child's behavior. Jodtis \& Smatana (2008) in his study to investigation the parenting style and moral concepts studied during adolescence. A total of 108 mothers and 92 fathers were investigated. In this study, they concluded that differences in parenting style of their parents divulge primarily to the personal qualification of the juvenile. Lavars and John (2008) in his study of family interactions and moral development were affected in children 2 years of 63 families. The results showed that moral development occurs when the parents level of dialogue with of children in actual flow lift with moral reasoning. Cornell and Frick (2007) to evaluate the effects of parenting styles in behavioral inhibition prediction empathy their preschool children's moral. The findings were that indicate behavioral inhibition and empathy in children depends on the type and quality of their parenting; however authoritarian parenting experienced higher levels of guilt among children(Marvin and Berkoet 2006). In his study with subject parent training to facilitate of moral development the children's reach the conclusion. Although moral development 
has long been attributed mostly to the effect of father and mother, but as a systematic and systemic nature of a special relationship there is little in this regard. They emphasized that to achieve the targeted communication parents should focus on the development of its quality parenting. Webster-Stratton \& Dahl (1995) in research with title teaching children with behavioral problems in a comparison educational interventions of family and child show that parents with behavioral problems and moral problems, often do not have importants skills training. The parents are in the use of violent rules and in consuming, inconsistent, fickle and negligent. There is little chance that their children lead. They punish their child's social behavior and reinforce negative behavior. In a study entitled the relationship between the family, the individual and the community in the early stages of the juvenile sex sexual expression Spanish by Cristofer et al. (1993) took place, showed that parents spend more time supervising their children have that are less prone to risky behavior and inappropriate and moral consciousness more than the others. Hoffman (1970) reviewed research related to parenting to acquiring result of the effects of parenting styles on children's moral development. The results showed that: (1) lack of love children and emphasized the power don't have a positive effect on their children's moral maturity. 2 . The inductive method on all three aspects of moral development - moral emotion, moral argument, and moral behavior has a positive impact (Hoffman, quoted Shaffer, 1996).

\section{Research Methodology}

This study from term of purpose, foundation and data collection is in the descriptive- correlation, this research in kindergartens city of Babol was done. The statistical population includes of 1320 students from preschool to kindergarten in the city Babol during the year 2014-2015. Which among them multistep random cluster sampling were selected 100 samples as members. Two questionnaires were used to collect information. 1- parenting style questionnaire baumrind that questionnaire included 30 questions that each 10 question measure one method of parenting and so measured the three authoritatively parenting style, permissive and despotic. In the present study, Cronbach's alpha was used to assess the reliability of the test. Results showed that the Cronbach's alpha coefficient is equal to 0.75

2- Inventory moral judgment MJT, test consisting of 50 questions about their child should take moral decisions. There is only one correct answer for each question. For every question right consider one score and for a wrong answer is zero. The maximum score of 50 and a minimum score of zero. The index will be the subject of moral judgment. In this study the internal validity of moral judgment, the internal consistency by Cronbach's alpha was obtained 0.61

Finally, to analyze the data, descriptive and inferential statistical methods was used by SPSS18 .

\section{The Main Hypothesis}

Between parenting styles and moral development of children 4 to 6 years there is a significant relationship between the city Babol? To investigate this hypothesis, Pearson's correlation coefficient was used that variable parenting style as a predictor variables and ethical growth as the dependent variable.

\begin{tabular}{|c|c|c|c|}
\hline \multicolumn{3}{|c|}{ Moral judgment } & \multirow{2}{*}{$\begin{array}{l}\text { dependent variabte } \\
\text { predictor variable }\end{array}$} \\
\hline )NumberN( & Significance level) $\mathrm{P}($ & Correlation coefficient) $\mathrm{r}($ & \\
\hline 100 & 0.01 & 0.647 & Parenting Styles \\
\hline
\end{tabular}

The results show that between parenting styles and moral judgment development in $P=0 / 01$ and the correlation coefficient $r=0 / 647$ was a positive significant relationship. Regarding the results, it can be said that the general hypothesis is confirmed.

\subsection{First Subhypotheses}

Between authoritatively parenting styles and moral judgment development of children 4 to 6 years there is a significant relationship between the city Babol? To investigate this hypothesis, Pearson's correlation coefficient was used that variable authoritatively parenting style as a predictor variables and moral judgment development as the dependent variable.

\begin{tabular}{|c|c|c|c|}
\hline \multicolumn{3}{|c|}{ Moral judgment } & \multirow{2}{*}{ dependent variable } \\
\cline { 1 - 2 } )NumberN( & Significance level $) \mathrm{P}($ & Correlation coefficient) $\mathrm{r}$ & predictor variable \\
\hline 38 & 0.01 & 0.760 & authoritatively Parenting Styles \\
\hline
\end{tabular}


The results show that between authoritatively parenting styles and moral judgment development in $P=0 / 01$ and the correlation coefficient $r=0 / 760$ was a positive significant relationship. Regarding the results, it can be said that the First Subhypotheses is confirmed.

\subsection{Second Subhypotheses}

Between despotic parenting styles and moral judgment development of children 4 to 6 years there is a significant relationship between the city Babol? To investigate this hypothesis, Pearson's correlation coefficient was used that variable despotic parenting style as a predictor variables and moral judgment development as the dependent variable.

\begin{tabular}{|c|c|c|c|}
\hline \multicolumn{3}{|c|}{ Moral judgment } & \multirow{2}{*}{$\begin{array}{c}\text { dependent variabte } \\
\text { predictor variable }\end{array}$} \\
\hline )NumberN( & Significance level $) \mathrm{P}($ & Correlation coefficient $) \mathrm{r}($ & despotic Parenting Styles \\
\hline 35 & 0.01 & $0.541-$ & \\
\hline
\end{tabular}

The results show that between despotic parenting styles and moral judgment development in $\mathrm{P}=0 / 01$ and the correlation coefficient $r=-0 / 541$ was a positive significant relationship. Regarding the results, it can be said that the second Subhypotheses is confirmed.

\subsection{Third Subhypotheses}

Between permissive parenting styles and moral judgment development of children 4 to 6 years there is a significant relationship between the city Babol? To investigate this hypothesis, Pearson's correlation coefficient was used that variable permissive parenting style as a predictor variables and moral judgment development as the dependent variable.

\begin{tabular}{|c|c|c|c|}
\hline \multicolumn{3}{|c|}{ Moral judgment } & \multirow{2}{*}{ dependent variable } \\
\cline { 1 - 2 } )NumberN( & Significance level $) \mathrm{P}($ & Correlation coefficient) $\mathrm{r}(n)$ & Predictor variable \\
\hline 27 & 0.01 & 0.283 & Permissive Parenting Styles \\
\hline
\end{tabular}

The results show that between Permissive parenting styles and moral judgment development in $P=0 / 01$ and the correlation coefficient $r=0.283$ was not a positive significant relationship. Regarding the results, it can be said that the third Subhypotheses is not confirmed.

\subsection{Forth Subhypotheses}

Styles of parenting predict the moral development of children 4 to 6 years? To determine the predictive power of parenting styles (authoritative, despotic, permissive) components moral development of children 4 to 6 years of stepwise multiple regression analysis were used.

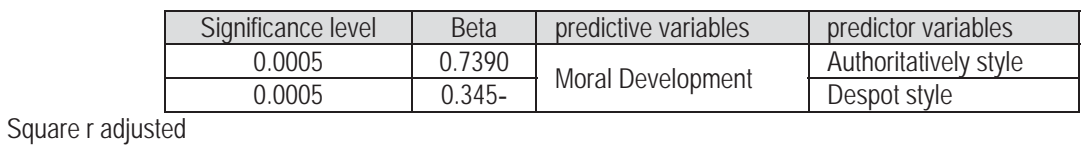

$0005.647,0.0<P ، 386 / 168=F$

The results show that both methods parenting styles authoritative, despotic have predictive power components moral development of children. Permissive parenting style was not a significant predictor. it can be said that the fourth Subhypotheses is confirmed.

\section{Conclusion}

This research with purpose the relationship between parenting styles and moral judgment development children 4-6 years in Babol city was done. Statistical analysis showed that between parenting styles (Authoritative, Permissive and despotic) and moral judgment development were significant relate. Healthy parenting style, according to the natural characteristics of the child and guided by prophets and God's guidance as watching the parents and their accountability before God and 
establish an all-round development of natural talent and indigenous children, and the extremes in the use of educational methods and deliver the child to the goals of higher education in the creation of his good character. Grow of children see the interaction between their properties and those who deal with them. However, the balance and the effect of socialization of children and parents in the most difficult aspect of this process are two-pronged. So that the empirical analysis it is very difficult (Gross and Leighton, 1988).

The primary control your child's behavior, mainly through external factors, in particular, the presence of the authorities or fear of punishment is established. In fact, the moral values to be searched in the external aspects of events and the material needs. Food and children's emotional dependence on sources of support, including parents cause children affected by parental interaction styles are encountered in various fields of fundamental growth including behavioral style, moral judgments and by the their parents. Since the methods of treatment and interacting with child to the purpose of the directive is to deal with various human phenomena. It can be said that the influence of this factor in the development and optimization of moral development is affected.

Authoritative parent's children with the development of autonomy and raising decision-making a positive impact and improving the way decisions are moral issues of their children. The reduce limits and share of children in the decision-making causes the children to learn ways to deal with different aspects of a phenomenon from the level of their knowledge beyond their core. Authoritative style of acceptance and intimacy in a relationship cause increased psychosocial development, self-esteem, self-confidence, independence and self-control which each of these factors can also be effective in creating growth internalized norms of morality. Children grown in violent authoritarian style and strict mostly to act upon behavioral feedback and this is this is very dependent and consistent with the child's experience, Because children assumed that the only source of power is their reference accuracy of their behavior and according to their behavior act or desist from action. Authoritarian parents by creating many limitations and the high demand of their children and prevent of opportunity to make decisions and sometimes even decide to instead of them. The child realizes it should bring up moral issues profit-benefit themselves in terms of human and moral reasons. In pattern very restrictive strict style, parents designed strict laws, they expect absolute obedience and precise and rarely explain to children, often emphasis for obtaing of purpose is punishment and to strictly control their children, so that children in the lowest level of empathy with her. The permissive parents due for freedom in decision-making sometimes witness growth fundamentals moral judgments on the other hand, The lack of parental support and very low levels of demand, many of the children in this style in their behavior can not put any limitations as an indicator of proper behavior and Usually social interactions with peers are failing. Darling (1999) points out in his study to the subject that children who have grown in permissive style often in trouble determining the norm in proper moral behavior. Parenting style to predict the development of moral judgment. Families that are considered to support children's internal powers and authoritative and reasonable compared to children whose families come out permissive or authoritarian, social development, obtaine self-esteem and mental health higher. They devote all their attention to correcting the problem and never try to make him afraid and confused and or blame him. This parents attention to the problems of children as a problem that needs a solution, in this model education, children do not rejection and beyond that he cites inappropriate behavior, attention, and at the same time he also considered positive aspects.

\section{Suggestions}

According to the data analysis and the results, proposals presented: The findings of this study may help in schools, kindergartens and organizations such as the education and well-used. Consultants and practitioners in education from findings on parenting skills training in parenting workshops and orientation of parents in educating their children. Future researchers trying with more control of confounding variables and age range of the sample in generalizing the results of this research.Researchers study other factors affecting the development of moral judgment in children, such as problem solving, life skills and other resources under their control children, study. It is recommended that experimental or quasiexperimental methods to control the effects of questionnaire used to assess relationships between variables.

\section{References}

Akrami, Nahid (1371), comparing the development of moral judgment in children and juvenile offenders and normal effect of family circumstances, the Master's thesis (unpublished) TMU

Azadi, Shahdokht (1382). Investigating the relationship between parenting style gingerly city girls Nurabad, master's thesis, general psychology, University of Alzahra.

Boromand Nasab, Masoud. (1373). "The relationship between parenting style with attitude and locus of control and academic 
performance of students of junior city of Dezful" master's thesis, Sahid Chamran University, Faculty of Education and Psychology.

Pour Abdolym, Muhammad; Kadivar, Parvin; Homayoni, Ali Reza. (1387),

"The relationship between mothers' parenting practices (authoritative, authoritarian, permissiveness) and child perception of practices and locus of control and self-concept of children", knowledge and research in psychology, number thirty-seven-Fall 1387; pp. 128-107.

Zahrakar, Kianoush (1387). Investigating the relationship between parenting style and parental mental health of adolescents in Eslamshahr City, Journal of Modern Thoughts in Education, 3, 2-91-72.

Seyed Mousavi, Parisa Sadat, Nad Ali, Hussein, Ghanbari, Saeid. (1387), "The Relationship between parenting styles and externalizing symptoms in children 7 to 9 years", Journal of Family Research, the fourth year / No. 13, Spring 1387.

Sharafi Jafjiri, Abas. (1386). The relationship of parents with pre-school children, Negah weekly, Tehran: Education Publishing.

Mohammadi, Zohreh. (1384). The power of predictive identification of children by parents in the parenting dimensions between male and female students of Shiraz University, Shiraz University master's thesis.

Baumrind, D. (1991). Effective Parenting during the early adolescent In P. A. Cowan \& E. M. Hetherington (Eds.), Family transitions (Vol. 2, PP. 111-163). Millsdale NJ: Erlbaum.

Baumrind, D. (2005). Patterns of parental authority and adolescent outonomy. New Direction for child and adolescent Development,( 108), 61-69.

Colby,A.,Kohlberg,L.,Speicher, B., Hever, A.,Candee,D., Gibbs, J.,\& power,C(1987). The measurement of moral judgment (vol.I). Cambridge, England: Cambrige University press.

Collins, W. A., \& Madsen, S. D. (2003). Developmental change inparenting interaction. In L. Kuczynski (Eds.), Handbook of dynamicsin parent - child relations (pp. 49-66). California: sage publications, Inc.

Cornell, A. H., \& Frick, P. J. (2007). The moderating effects of parenting styles in the association

Darling, N., \& Steinberg, L. (1993). Parenting style as context: An integrative model. Psychological Bulletin, 113 (3), 487-496.

Development: Specificity of Behavior and Context. Social Development, 2014.

Judith G. Smetana.(2008). Parenting Styles and Conceptions of Parental Authority during Adolescence. Child Development. pages 299316 , April .

Kazodin , A.E. \& etal.(2005). The therapeutic ahiance in cognitive- behavioral treatment of children referred for oppositional , aggressive , and antisocial behavior. Journal of consulting and clinical psychology, 73, 726-730.

Kazodin , A.E. (2006). Arbitrary Metrics: I implications for identifying evidence- based treatments. AmericanPsychologist, 61,42-49.

Kohlberg, L. (1966). Cognitive stages and preschool education. Human Development, 9,5-17.

Kohlberg, L. (1981). Essays on moral development(vol.I).New York: Harper \& Row

Laible, D.\& Thompson. (2002). Mother- child conflict in toddler years: lessons in emotion, morality, and relationship child development, 73,1187-1203.

Lawrence J. W.\& John H. T.(2008). Family Interactions and the Development of Moral Reasoning. Child Development. pages 264-283, April 2008.

Maccoby, E. E. (1984). Socialization and developmental change.Child Development, 55, 517-528.

Mairin E. Augustine and Cynthia A. Stifter.(2014). Temperament, Parenting, and Moral

McNally, S., Eisenberg, N., \& Harris, J. D. (1991). Consistency andchange in maternal child - rearing practices and values: A longitudinalstudy. Child Development, 62, 190-198. 